Friedrich-Loeffler-Street 23, D-17475, Greifswald, Germany. Email: beate.koch@uni-greifswald.de

Statement of Interest: None declared.

\section{REFERENCES}

1 Koch B, Schäper C, Ittermann $\mathrm{T}$, et al. Reference values for cardiopulmonary exercise testing in healthy volunteers: the SHIP study. Eur Respir J 2009; 33: 389-397.

2 John U, Greiner B, Hensel E, et al. Study of Health In Pomerania (SHIP): a health examination survey in an east German region: objectives and design. Soz Praventivmed 2001; 46: 186-194.
3 Neder JA, Nery LE, Castelo A, et al. Prediction of metabolic and cardiopulmonary responses to maximum cycle ergometry: a randomised study. Eur Respir J 1999; 14: 1304-1313.

4 Wasserman K, Hansen JE, Sue DY, et al. Principles of Exercise Testing and Interpretation: Including Pathophysiology and Clinical Applications. 4th Edn. Philadelphia, Lippincott Williams and Wilkins, 2004.

5 Unverdorben M, der Bijl A, Potgieter L, et al. Effects of levels of cigarette smoke exposure on symptom-limited spiroergometry. Prev Cardiol 2007; 10: 83-91.

\title{
Sex differences in COPD
}

\section{To the Editors:}

I read with interest the elegant study by DE TORRES et al. [1] indicating that female patients with chronic obstructive pulmonary disease (COPD) have better survival than male patients. As eloquently discussed by the authors, despite previous conflicting data, several other recent studies support the survival advantage of females with this disease [1]. However, the underlying mechanisms for this survival advantage remain unknown. DE TORRES et al. [1] speculate that the increased mortality in males may be due to a higher prevalence of cardiovascular disease and/or lung cancer in this population. I propose an additional potential mechanism to explain the sex differences in COPD mortality.

Interestingly, females have been demonstrated to exhibit less severe hypoxic pulmonary hypertension $(\mathrm{PH})$ than males (reviewed in [2]). Multiple studies have documented that females have a lower incidence of high-altitude pulmonary oedema (characterised by marked hypoxic vasoconstriction) [2, 3]. These mostly observational studies have been followed by mechanistic animal experiments demonstrating that females exhibit less severe hypoxic pulmonary vasoconstriction and hypoxic PH than males [4,5]. Only recently have some of the molecular mechanisms been identified that may potentially contribute to the observed sex differences in acute and chronic hypoxic $\mathrm{PH}$ [6-8]. Based on the results demonstrated by $\mathrm{DE}$ TORRES et al. [1], it is feasible that the increased survival observed in females is, at least in part, due to less severe hypoxic $\mathrm{PH}$ in this patient population. Of particular interest is the finding that all-cause mortality was increased in males in all four BODE (body mass index, airflow obstruction, dyspnoea, exercise capacity) quartiles, while respiratory mortality was increased in males only in the highest BODE quartile, indicating that the males in this quartile may potentially have had more severe hypoxic $\mathrm{PH}$ than their female counterparts.

Right ventricular (RV) function is an important prognostic indicator in patients with $\mathrm{PH}$ [9]. Even subtle changes in indices
RV function have been demonstrated to significantly impact on survival [9]. Interestingly, a recent study demonstrated that female patients with pulmonary arterial hypertension have a higher RV ejection fraction than males (controlled for left ventricular function and haemodynamics) [10]. This finding is in concordance with multiple reports indicating that females tolerate various forms of left ventricular injury better than males (reviewed in $[2,11]$ ). Since severe COPD negatively affects RV function, it is therefore conceivable that RV function in female COPD patients may be better preserved than in males.

The study by DE TORRES et al. [1] adds to the growing evidence that female sex is associated with a better prognosis in several conditions associated with vascular dysfunction, hypoxia and inflammation, such as myocardial ischaemia, sepsis, severe trauma, acute lung injury and hypoxic PH [2]. While human studies yielded more conflicting results than laboratory investigations, most human studies did not control for the potentially confounding effects of menstrual cycle, menopause, hormone replacement therapy or changes in sex-hormone binding proteins. In addition, extra ovarian production of sex hormones in the adipose tissue of males and females, or prolonged effects of previous hormone replacement therapy in post-menopausal females may play clinically relevant roles. These observations underline the need for rigorously controlled clinical studies investigating the role of sex differences in COPD and other pulmonary diseases.

Understanding the mechanisms of sex differences in COPD may allow for the development of targeted nonhormonal therapies for both sexes. For now, it appears that, at least among patients with COPD and hypoxic pulmonary hypertension, it is better to be female.

\section{T. Lahm}

Dept of Medicine, Division of Pulmonary, Allergy, Critical Care and Occupational Medicine and Richard L. Roudebush VA Medical Center, Indiana University School of Medicine, Indianapolis, IN, USA. 
Correspondence: $1481 \mathrm{~W}$ 10th Street, VA 111P-IU, Indianapolis IN, 46202, USA. E-mail: tlahm@iupui.edu

Statement of Interest: A statement of interest for T. Lahm can be found at www.erj.ersjournals.com/misc/statements.dtl

\section{REFERENCES}

1 de Torres JP, Cote CG, Lopez MV, et al. Sex differences in mortality in patients with COPD. Eur Respir J 2009; 33: 528-535.

2 Lahm T, Crisostomo PR, Markel TA, et al. The effects of estrogen on pulmonary artery vasoreactivity and hypoxic pulmonary vasoconstriction: potential new clinical implications for an old hormone. Crit Care Med 2008; 36: 2174-2183.

3 Hultgren HN, Lopez CE, Lundberg E, et al. Physiologic studies of pulmonary edema at high altitude. Circulation 1964; 29: 393-408.

4 Rabinovitch M, Gamble WJ, Miettinen OS, et al. Age and sex influence on pulmonary hypertension of chronic hypoxia and on recovery. Am J Physiol 1981; 240: H62-H72.

5 Wetzel RC, Sylvester JT. Gender differences in hypoxic vascular response of isolated sheep lungs. J Appl Physiol 1983; 55: 100-104.

6 Lahm T, Crisostomo PR, Markel TA, et al. Selective estrogen receptor-alpha and estrogen receptor-beta agonists rapidly decrease pulmonary artery vasoconstriction by a nitric oxidedependent mechanism. Am J Physiol Regul Integr Comp Physiol 2008; 295: R1486-R1493.

7 Lahm T, Patel KM, Crisostomo PR, et al. Endogenous estrogen attenuates pulmonary artery vasoreactivity and acute hypoxic pulmonary vasoconstriction: the effects of sex and menstrual cycle. Am J Physiol Endocrinol Metab 2007; 293: E865-E871.

8 Resta TC, Kanagy NL, Walker BR. Estradiol-induced attenuation of pulmonary hypertension is not associated with altered eNOS expression. Am J Physiol Lung Cell Mol Physiol 2001; 280: L88-L97.

9 Haddad F, Hunt SA, Rosenthal DN, et al. Right ventricular function in cardiovascular disease, part I: anatomy, physiology, aging, and functional assessment of the right ventricle. Circulation 2008; 117: 1436-1448.

10 Kawut SM, Al-Naamani N, Agerstrand C, et al. Determinants of Right Ventricular Ejection Fraction in Pulmonary Arterial Hypertension. Chest 2009; 135: 752-759.

11 Murphy E, Steenbergen C. Gender-based differences in mechanisms of protection in myocardial ischemia-reperfusion injury. Cardiovasc Res 2007; 75: 478-486.

DOI: $10.1183 / 09031936.00038909$

\section{From the authors:}

We appreciate the comments of T. Lahm about our recently published article [1]. He suggests that one possible explanation for the better survival observed in females with chronic obstructive pulmonary disease (COPD) compared to that of males with COPD may be the presence of less severe hypoxemic vasoconstriction and, therefore, pulmonary hypertension $(\mathrm{PH})$ and/or right ventricular hypertrophy in females compared with males. Although he provides indirect evidence to support his comments, we have a few problems with this mechanism being an important one. This is based on the fact that in our study population only $18 \%$ of participants had Global Obstructive Chronic Lung Disease stage IV and 12\% were in quartile 4 of the BODE (body mass index, airflow obstruction, dyspnoea, exercise capacity) index, usually the type of individuals that develop hypoxaemia and PH. In fact, only 25 patients ( $~ 5 \%$ ) from our population were on long-term oxygen therapy, which would be the population where the likelihood of cor pulmonale is highest. However, the difference in mortality between females and males persisted across disease severity. Conversely, we do agree with his comments regarding the more severe patients, especially those with hypoxaemia, as was previously shown by the works of the MiYAmoto et al. [2], СROCKeTt et al. [3] and FRANKLIN et al [4].

A problem with T. Lahm's theory is that females with obstructive sleep apnoea syndrome have a higher mortality than males with obstructive sleep apnoea syndrome $[5,6]$. If we accept that sleep apnoea represents an example of intermittent hypoxaemia and increased pulmonary artery pressure, and is usually associated with right ventricular hypertrophy and adipose tissue, T. Lahm's proposed theory to explain the better survival effect in females with COPD is not quite that clear.

Greater effort in the research field is needed in order to clarify the increasingly important issue of sex and disease expression. However, the interesting hypothesis proposed by T. Lahm sheds more light on to this dark field; we are thankful for his insight.

\section{J.P. de Torres*, C. Casanova ${ }^{\#}$ and B.R. Celli ${ }^{\star}$}

*Pulmonary Dept, Clinica Universidad de Navarra, Pamplona, \#Pulmonary Dept, Hospital Universitario Ntra Sra de Candelaria, Tenerife, Spain, and 'Caritas St Elizabeth's Medical Center, Boston, MA, USA.

Correspondence: J.P. de Torres, Unidad de Investigacion Respiratory, Carretera del Rosario s/n, Santa Cruz de Tererife 38010, Spain. E-mail: jupa65@hotmail.com

Statement of Interest: None declared.

\section{REFERENCES}

1 de Torres JP, Cote CG, López MV, et al. Sex differences in mortality in patients with COPD. Eur Respir J 2009; 33: 528-535.

2 Miyamoto K, Aida A, Nishimura M, et al. Gender effect on prognosis of patients receiving long-term home oxygen therapy. The Respiratory Failure Research Group in Japan. Am J Respir Crit Care Med 1995; 152: 972-976.

3 Crockett AJ, Cranston JM, Moss JR, et al. Survival on long-term oxygen therapy in chronic airflow limitation: from evidence to outcomes in the routine clinical setting. Intern Med J 2001; 31: 448-454.

4 Franklin KA., Gustafson T., Ranstam J., et al. Survival and future need of long-term oxygen therapy for chronic obstructive pulmonary disease: gender differences. Respir Med 2007; 101: 1506-1511.

5 Morrish E, Shneerson JM, Smith IE. Why does gender influence survival in obstructive sleep apnoea? Respir Med 2008; 102: 1231-1236.

6 Young T, Finn L. Epidemiological insights into the public health burden of sleep disordered breathing: sex differences in survival among sleep clinic patients. Thorax 1998; 53: Suppl. 3, S16-S19.

DOI: $10.1183 / 09031936.00061409$ 